\title{
Habitat characteristics and insecticide susceptibility of Aedes aegypti in the Ifakara area, south-eastern Tanzania
}

\author{
Najat F. Kahamba ${ }^{1,3^{*}}$, Alex J. Limwagu1', Salum A. Mapua', Betwel J. Msugupakulya ${ }^{1,3}$, Dickson S. Msaky', \\ Emmanuel W. Kaindoa ${ }^{1,2}$, Halfan S. Ngowo ${ }^{1,4}$ and Fredros O. Okumu ${ }^{1,2,3,4^{*}}$
}

\begin{abstract}
Background: Aedes-borne diseases such as dengue and chikungunya constitute constant threats globally. In Tanzania, these diseases are transmitted by Aedes aegypti, which is widely distributed in urban areas, but whose ecology remains poorly understood in small towns and rural settings.
\end{abstract}

Methods: A survey of Ae. aegypti aquatic habitats was conducted in and around Ifakara, a fast-growing town in south-eastern Tanzania. The study area was divided into $200 \times 200 \mathrm{~m}$ search grids, and habitats containing immature Aedes were characterized. Field-collected Ae. aegypti were tested for susceptibility to common public health insecticides (deltamethrin, permethrin, bendiocarb and pirimiphos-methyl) in the dry and rainy seasons.

Results: Of 1515 and 1933 aquatic habitats examined in the dry and rainy seasons, 286 and 283 contained Aedes immatures, respectively (container index, $\mathrm{Cl}: 18.9-14.6 \%$ ). In the 2315 and 2832 houses visited in the dry and rainy seasons, 114 and 186 houses had at least one Aedes-positive habitat, respectively (house index, HI: 4.9-6.6\%). The main habitat types included: (i) used vehicle tires and discarded containers; (ii) flowerpots and clay pots; and (iii) holes made by residents on trunks of coconut trees when harvesting the coconuts. Used tires had highest overall abundance of Ae. aegypti immatures, while coconut tree-holes had highest densities per habitat. Aedes aegypti adults were susceptible to all tested insecticides in both seasons, except bendiocarb, against which resistance was observed in the rainy season.

Conclusions: To our knowledge, this is the first study on ecology and insecticide susceptibility of Ae. aegypti in Ifakara area, and will provide a basis for future studies on its pathogen transmission activities and control. The high infestation levels observed indicate significant risk of Aedes-borne diseases, requiring immediate action to prevent potential outbreaks in the area. While used tires, discarded containers and flowerpots are key habitats for Ae. aegypti, this study also identified coconut harvesting as an important risk factor, and the associated tree-holes as potential targets for Aedes control. Since Ae. aegypti mosquitoes in the area are still susceptible to most insecticides, effective control could be achieved by combining environmental management, preferably involving communities, habitat removal and insecticide spraying.

Keywords: Aedes aegypti, Habitat characteristics, Insecticide susceptibility, Ifakara Health Institute, Dengue, Chikungunya, Tanzania

\footnotetext{
*Correspondence: nkahamba@ihi.or.tz; fredros@ihi.or.tz

${ }^{1}$ Environmental Health and Ecological Sciences Department, Ifakara Health Institute, P. O. Box 53, Ifakara, Tanzania

Full list of author information is available at the end of the article
}

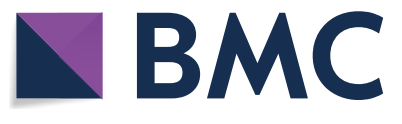

(c) The Author(s) 2020. This article is licensed under a Creative Commons Attribution 4.0 International License, which permits use, sharing, adaptation, distribution and reproduction in any medium or format, as long as you give appropriate credit to the original author(s) and the source, provide a link to the Creative Commons licence, and indicate if changes were made. The images or other third party material in this article are included in the article's Creative Commons licence, unless indicated otherwise in a credit line to the material. If material is not included in the article's Creative Commons licence and your intended use is not permitted by statutory regulation or exceeds the permitted use, you will need to obtain permission directly from the copyright holder. To view a copy of this licence, visit http://creativeco mmons.org/licenses/by/4.0/. The Creative Commons Public Domain Dedication waiver (http://creativecommons.org/publicdomain/ zero/1.0/) applies to the data made available in this article, unless otherwise stated in a credit line to the data. 


\section{Background}

In recent decades, significant attention has been paid to control mosquitoes that transmit malaria, leading to substantial progress since 2000 [1, 2]. However, other mosquito-borne diseases, such as dengue, yellow fever, chikungunya and Zika, which are transmitted by Aedes mosquitoes remain largely neglected. Golding et al. [3] showed that more than $90 \%$ of people at risk of vectorborne diseases are affected by at least two such diseases, malaria and dengue fever being the most prevalent. The WHO Global Vector Control Response (GVCR) initiative therefore recommended integrated approaches to address multiple vectors and vector-borne diseases [4]. Unfortunately, unlike malaria, for which effective prevention and treatment options are widely available, the Aedes-borne diseases still rely mostly on personal protection measures [5], even though vaccine trials are increasingly advanced [6].

In Tanzania, concerns about Aedes-borne diseases have become increasingly prominent in recent years, due to multiple outbreaks, detection of the viruses in humans, and widespread distribution of the Aedes mosquitoes [7-10]. Dengue cases have been reported in multiple regions in the country, including Dar es Salaam city, the islands of Zanzibar and Pemba, Mbeya and Iringa areas in the southern Tanzania, as well as Kilimanjaro in the north [11-13]. The most recent outbreak occurred in May 2019, when 1012 new cases were confirmed over just two weeks [14]. By September 2019, 6912 cases had been reported, including 13 deaths [14]. Most outbreaks of Aedes-borne diseases have been observed in urban areas, where densities of both the vectors and humans are high [11]. However, human mobility has also led to introduction of the viruses in rural areas and small towns [7]. Unfortunately, efforts against these diseases are hampered by the lack of proper medication or diagnostics [15-17]. Effective vector surveillance and control to prevent potentially infectious mosquito bites therefore remain core components of programmes targeting Aedes-borne diseases [5].

Current understanding of Aedes mosquitoes is largely based on studies in urban areas where the vector is most widespread [18]. Aedes aegypti, the most important of the Aedes species, is considered highly anthropophilic, and is a frequent breeder in artificial containers [19], common in urban settings [8]. Improper disposal of waste containers provides perfect breeding environment for Ae. aegypti mosquitoes. For example, in coastal Tanzania, used tires and disposed containers were identified as the most common aquatic habitats for Ae. aegypti [11, 20]. However, less is known regarding the ecology of these vectors in inland Tanzania, including small towns and rural settings. Yet, this is important to understand distribution of the vectors across the country, and more importantly to prevent introduction or spread of Aedes-borne arboviruses. To ensure effective control, such ecological studies should be complemented with investigations on susceptibility to commonly used public health insecticides [21, 22].

This study was therefore conducted to fulfil three key objectives: (i) investigate spatial distribution of $A e$. aegypti in Ifakara town in south-eastern Tanzania and its surrounding wards; (ii) characterize aquatic habitats of the mosquitoes in the area; and (iii) assess susceptibility of the mosquitoes to insecticides commonly used for vector control.

\section{Methods}

Study area

Surveys for Aedes immatures were conducted in Ifakara town and surrounding wards, namely, Lipangalala $(-8.16428,36.68964)$, Viwanja Sitini $(-8.13512$, 36.68413), Mlabani $(-8.13952,36.68964)$ and Katindiuka $(-8.13154,36.71165)$, all in the Kilombero valley in south-eastern Tanzania (Fig. 1). Ifakara town and Viwanja Sitini are characterized as urban, while the other three locations are rural. The area has an average altitude of $270 \mathrm{~m}$, annual rainfall of $1200-1800 \mathrm{~mm}$, relative humidity of $51-71 \%$, and daily temperatures of $20-32.6{ }^{\circ} \mathrm{C}$ [23]. The area experiences short rains in November and December, which is interrupted by dry months from January to March. Heavy rains continue from April to May or June, followed by dry July and September. This area is growing rapidly with total population now estimated at 67,500 , based on the $2.7 \%$ annual growth from the last census in 2012 [24].

\section{Selection of sampling sites}

The study area was divided into grids measuring $200 \times 200 \mathrm{~m}$, in ArcGIS 10.4 environment (ESRI, USA) as previously described by Mwangungulu et al. [25], and the grids assigned unique identifiers (Fig. 2). The grids were overlaid with household geolocation data initially collected by Ifakara Health Institute's Health and Demographic Surveillance System [26]. The data were updated using population density maps from Google satellite imagery and a high-resolution settlement layer (HRSL), created by the Facebook Connectivity Lab and Centre for International Earth Science Information Network (CIESIN) [27].

From each ward, 34 grids containing human habitation or other actively used buildings were selected as search grids. For each search grid, houses or buildings nearest to the centroid were identified as starting points for Aedes habitat searches. Where no informed consent was obtained, the next nearest consenting household 


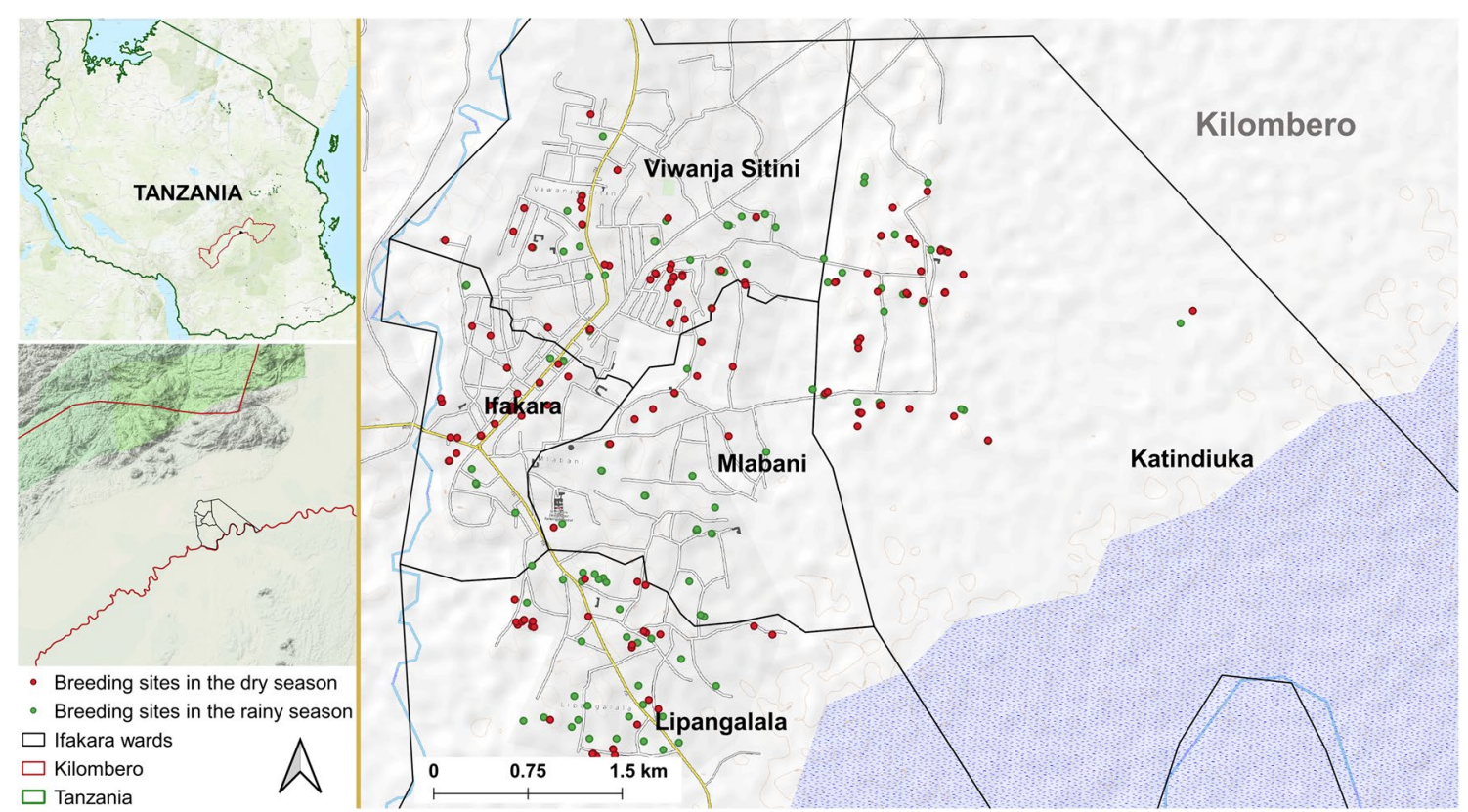

Fig. 1 Study area: map of Ifakara town and its surrounding wards showing locations where Ae. aegypti immatures were sampled in dry and rainy seasons

was selected. From the starting points, all potential aquatic Aedes habitats were searched within $100 \mathrm{~m}$ radii, visiting each search grid twice in the dry season and twice in the rainy season. In total, 170 search grids were visited in each round of the survey. Important features such as schools, marketplaces, worship areas, health facilities and water pumps were also mapped using handheld GPS receivers (Magelan eXplorist GC, USA).

\section{Sampling of mosquito immatures and characterization of their aquatic habitats}

Sampling for Aedes immatures and characterization of their habitats was focused on natural and artificial waterholding objects such as tree-holes, used tires, wells and discarded containers and animal feeding containers. Others included coconut shells, tarpaulins, broken grasses and other small objects that could potentially hold water longer than three days. All sites with Ae. aegypti larvae or pupae were georeferenced using handheld GPS. The habitats were characterized by: (i) location; (ii) size; (iii) apparent water color; (iv) presence of vegetation; (v) presence of shading; (vi) source of water in the habitat; (vii) whether the habitat was movable or not; and (viii) environmental and social activities surrounding the habitats.

Larvae and pupae were sampled from each of the identified habitats using standard $350 \mathrm{ml}$ dippers, or a smaller $70 \mathrm{ml}$ dipper in cases where habitats were too small to sample using the standard dipper. The larvae and pupae were placed in white trays for morphological identification, using pictorial keys created by the USA Centers for Disease Control and Prevention [28]. They were then sorted, counted and data recorded by habitat type, location and survey instance. The Aedes mosquito sampling was done from November 2018 to May 2019, with a break in February 2019.

\section{Mosquito rearing and identification of emergent adults}

The sampled Aedes larvae and pupae from the different habitats were transferred to the vector biology laboratory (VectorSphere) at Ifakara Health Institute (IHI) for rearing and eventual morphological identification of emergent adults. The larvae were fed on Tetramin ${ }^{\circledR}$ baby fish food and maintained at temperatures of $26 \pm 2{ }^{\circ} \mathrm{C}$ and a relative humidity of $82 \pm 10 \%$. Pupae were collected each morning, counted and transferred to netting cages $(30 \times 30 \times 30 \mathrm{~cm})$. Emergent adults were identified under stereomicroscopes using taxonomic keys for Aedes mosquitoes [28].

\section{Bioassays for insecticide susceptibility tests}

Bioassays were performed following WHO insecticide susceptibility test guidelines $[29,30]$. Female Ae. aegypti, 3-5 days-old, originating from each ward were tested against public health insecticides as follows: two pyrethroids (deltamethrin: 0.05\%; and permethrin: 0.75\%), 

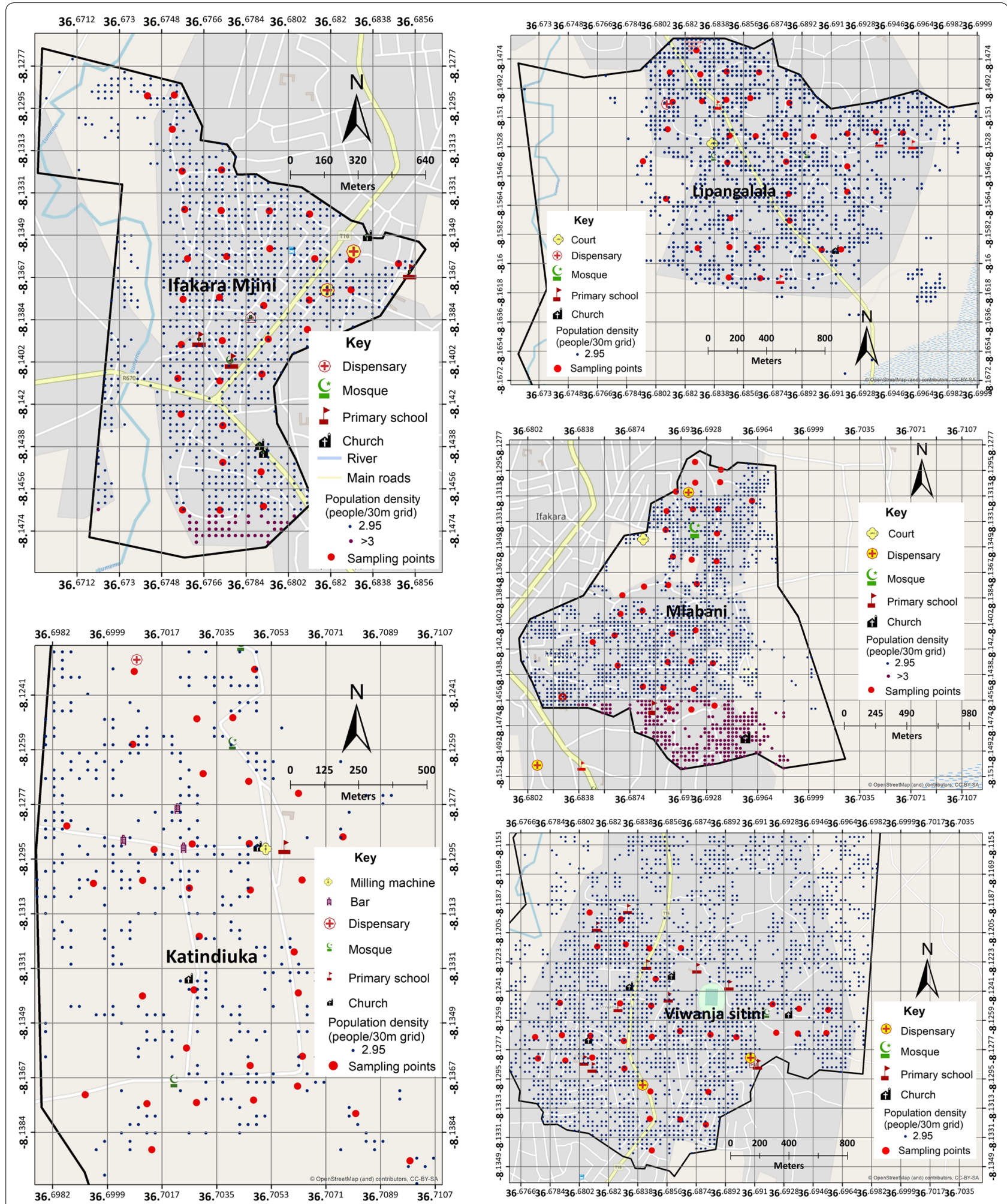

Fig. 2 Selected grids in the study area, which were sampled for conducting Ae. aegypti larval surveys in dry and rainy seasons. Estimated population densities are also shown 
one organochloride (dieldrin: 4\%), one organophosphate (pirimiphos-methyl: $0.25 \%$ ) and one carbamate (bendiocarb: $0.1 \%)$. The two pyrethroids included both types I \& II, respectively. The insecticides were selected because they represented the common classes of insecticides for public health generally and in the study area. In each experiment 120-150 mosquitoes were used, so that there were 20-25 individuals per test. Untreated controls were included, and the mosquitoes were initially observed for 60 minutes to observe knockdown at 10, 15, 20, 30, 40, 50 and $60 \mathrm{~min}$. The exposed and non-exposed mosquitoes were then provided with $10 \%$ glucose and maintained at $28.0 \pm 1.0{ }^{\circ} \mathrm{C}$ and $80 \pm 10 \%$ relative humidity, then overall mortality observed after 24 hours.

\section{Measurements of mosquito wing lengths}

Emergent adults from different wards were assessed by measuring their wing lengths. All the mosquitoes had been originally collected as larvae or pupae. The mosquitoes were anaesthetized at $-10{ }^{\circ} \mathrm{C}$ for $5 \mathrm{~min}$. Wings were then removed from male and female mosquitoes (either the left or the right wing). Drops of distilled water were used to fix the wings onto glass slides. Wing lengths were measured, as the distance from the apical notch to the auxiliary margins, under stereo zoom microscope at $10 \times$ magnification using a micrometer ruler.

\section{Data analysis}

Statistical analyses were carried out in the open-source R statistical software, version 3.231 [31]. Descriptive analysis was performed to compare larval densities in different wards and seasons. Densities obtained from the $70 \mathrm{ml}$ dipper were compared to those from the standard $350 \mathrm{ml}$ dipper and a correlation coefficient calculated across all collections. Using this coefficient, the densities assessed by the small dipper were all converted into the standard dipper, so that all subsequent analyses were done on the standard dipper.

Generalized linear models with Poisson distributions for count data were used to model the number of larvae collected per dipper as a response variable against season and habitat type as a fixed factor. Logistic regression was also used to assess associations between positivity of different habitat types for Aedes larvae (proportion of individual habitats of each type that had Aedes larvae or pupae). The relative risk (RR), odds ratios (OR) and their 95\% confidence intervals $(95 \% \mathrm{CI})$ were estimated. The dabestr package was used to assess mean differences in larval abundance between wards and seasons.

Larval indices, namely container index (CI, the proportion of containers infested with Ae. aegypti larvae or pupae), house index (the proportion of houses infested with Ae. aegypti larvae or pupae) and Breteaux Index (the number of infested containers per 100 houses) were also calculated by ward or season [22, 32, 37].

Mosquito wing lengths were compared using one-way ANOVA, followed by Tukey's post-hoc tests to assess mean differences between wards for both male and female mosquitoes. Susceptibility status of Ae. aegypti was computed according to the WHO guidelines [29] and log-probit analysis was used to compute mean duration at which $50 \%\left(\mathrm{KD}_{50}\right)$ and $95 \%\left(\mathrm{KD}_{95}\right)$ of the exposed mosquitoes were knocked down.

Spatial and seasonal distribution of Aedes immatures were analyzed by geostatistical in ArcGIS 10.4 (ESRI, USA). Inverse distance weighted (IDW) interpolation technique $[33,34]$ was used to visualize the areas with high larval densities. Representation of IDW maps show patterns based on the distance from one observed point to another. Known values (number of larvae) were used as key input feature to estimate unknown locations within $400 \mathrm{~m}$ range based on estimated average flight range of Aedes mosquitoes [35, 36, 37]. Geoprocessing extents and masks were defined to match the study area.

\section{Results \\ Larval indices}

A total of 1515 breeding sites were visited in the dry season and 1933 in the rainy season. Of these, 286 (18.87\%) in the dry season and 283 (14.64\%) in the rainy season were positive for Aedes immatures. The proportions of Aedes-infested habitats and houses varied across wards and seasons (Table 1). In the dry season, high container indices (CIs) were observed in Katindiuka, Viwanja Sitini and Ifakara town wards, while in the rainy season, high CIs were recorded in Ifakara town, Viwanja sitini and Lipangalala wards.

With regard to house indices (HI), 2315 and 2832 houses were visited in the dry and rainy season surveys, of which, $114(4.9 \%)$ and 186 (6.6\%) had at least one positive habitat, respectively. Viwanja sitini ward had the highest HI during the dry season, while Ifakara town had the highest $\mathrm{HI}$ in the rainy season. Compared to the dry season, $\mathrm{HI}$ increased during the rainy season in all wards expect Lipangalala (Table 1). It was also observed that Viwanja Sitini ward had highest Breteaux Index (BI) in both seasons.

\section{Densities of Ae. aegypti immatures, their distribution and aquatic habitats}

A total of 63,470 larvae or pupae were collected from all wards. Of these, $76.3 \%(n=48,459)$ were Ae. aegypti, $20.9 \%(n=13,253)$ were Culex, and $2.8 \%(n=1758)$ were identified as other Aedes spp. In the dry season surveys, Ifakara town produced nearly one third of all immature Aedes and more than one third of immature Culex. In the 
Table 1 Summary of Ae. aegypti larval survey indices by ward and season

\begin{tabular}{|c|c|c|c|c|c|c|}
\hline \multirow[t]{2}{*}{ Wards } & \multicolumn{3}{|c|}{ Dry season } & \multicolumn{3}{|c|}{ Rainy season } \\
\hline & $\mathrm{Cl}(\%)$ & HI (\%) & BI (\%) & Cl (\%) & $\mathrm{HI}(\%)$ & $\mathrm{BI}(\%)$ \\
\hline Ifakara town & 21.4 & 4.18 & 16.74 & 27.4 & 7.12 & 9.54 \\
\hline Katindiuka & 18.7 & 4.45 & 9.37 & 11.2 & 6.78 & 7.22 \\
\hline Viwanja sitini & 29.5 & 6.67 & 20.28 & 26.2 & 6.75 & 15.25 \\
\hline Mlabani & 13.0 & 3.33 & 5.12 & 11.9 & 6.58 & 10.53 \\
\hline Lipangalala & 21.4 & 6.44 & 8.44 & 19.6 & 5.11 & 11.11 \\
\hline
\end{tabular}

Abbreviations: $\mathrm{Cl}$, container index (ratio of larval infested to total inspected containers); $\mathrm{HI}$, house index (ratio of larval infested to all inspected houses); $\mathrm{Bl}$, Breteau index (ratio of positive containers per 100 houses inspected)

rainy season however, Viwanja Sitini had more than one third of the Aedes immatures, while Katindiuka produced more than half of all Culex. Most Culex were found in the dry season, while Aedes were more prevalent in the rainy season (Table 2).

Overall, most Aedes larvae were obtained from used tires and clay pots followed by other containers such as discarded tins, buckets, drums and animal feeding pots (Fig. 3). However, coconut tree-holes and flowerpots had far higher numbers of larvae per dip compared to all other habitat types, in the dry season (Table 3). Likelihood of getting larvae in individual tree-holes was three times higher than in used vehicle tires (RR: 3.00, 95\% CI: 2.58-3.50, $P<0.01)$. However, in the rainy season, higher larval densities were observed in other habitats (Table 3).

\section{Positivity of different habitat types for Ae. aegypti immatures}

Positivity of the habitats for Ae aegypti are summarized in Table 4. By assessing proportions for each type of habitat, it was determined that used tires were the most commonly infested with Ae. aegypti (89\% positivity), followed by containers (86\% positivity) and clay pots ( $82 \%$ positivity), garage pits (64\% positivity) and others ( $90 \%$ positivity). Majority of the positive breeding sites were movable, associated with human activities, or were found in and around residential areas, commercial places and garages. Significantly higher Ae. aegypti positivity was observed in the rainy season than in the dry season. Additionally, the number of positive habitats was higher if they had clear water than turbid water.

\section{Spatial and seasonal distribution of Ae. aegypti immatures}

The spatial distribution of Ae. aegypti immatures varied between the dry and rainy season (Fig. 4). In the dry season, the highest infestation was from the center of Ifakara town toward western parts of Katindiuka ward. In contrast, in the rainy season most infested locations were in southern Lipangalala and in Viwanja sitini (Fig. 4).

Generally, fewer breeding sites were observed in the dry season compared to the rainy season in all study sites, although the actual abundance varied significantly between sites. Ifakara town consistently had higher mean number of Aedes larvae than other wards across seasons (Fig. 5). The residual mean differences of larval abundance were estimated between study ward.

\section{Susceptibility of adult Aedes aegypti mosquitoes to insecticides}

Aedes aegypti females were generally susceptible to all four classes of insecticides. Only in a few instances did

Table 2 Sampled populations of Aedes and Culex larvae collected in all aquatic habitats in Ifakara town and its surrounding wards

\begin{tabular}{|c|c|c|c|c|c|c|c|c|c|c|}
\hline \multirow[t]{3}{*}{ Wards } & \multicolumn{4}{|c|}{ Dry season } & \multicolumn{4}{|c|}{ Rainy season } & \multicolumn{2}{|l|}{ Total } \\
\hline & \multicolumn{2}{|l|}{ Aedes } & \multicolumn{2}{|l|}{ Culex } & \multicolumn{2}{|l|}{ Aedes } & \multicolumn{2}{|c|}{ Culex larvae } & \multirow{2}{*}{$\begin{array}{l}\text { Aedes } \\
n\end{array}$} & \multirow{2}{*}{$\begin{array}{l}\text { Culex } \\
n\end{array}$} \\
\hline & $n$ & $\%$ & $n$ & $\%$ & $n$ & $\%$ & $n$ & $\%$ & & \\
\hline Ifakara town & 5325 & 32 & 4217 & 39 & 6769 & 20 & 0 & 0 & 12094 & 4217 \\
\hline Katindiuka & 2845 & 17 & 1240 & 11 & 2383 & 7 & 919 & 37 & 5228 & 2159 \\
\hline Viwanja sitini & 3527 & 21 & 3116 & 29 & 11652 & 35 & 0 & 0 & 15179 & 3116 \\
\hline Mlabani & 1833 & 11 & 826 & 8 & 7698 & 23 & 15 & 1 & 9531 & 841 \\
\hline Lipangalala & 3284 & 20 & 1386 & 13 & 4901 & 15 & 1534 & 62 & 8185 & 2920 \\
\hline
\end{tabular}

Note: $\mathrm{n}$ denotes number of larvae collected, $\%$ denotes percentage of larvae by ward 

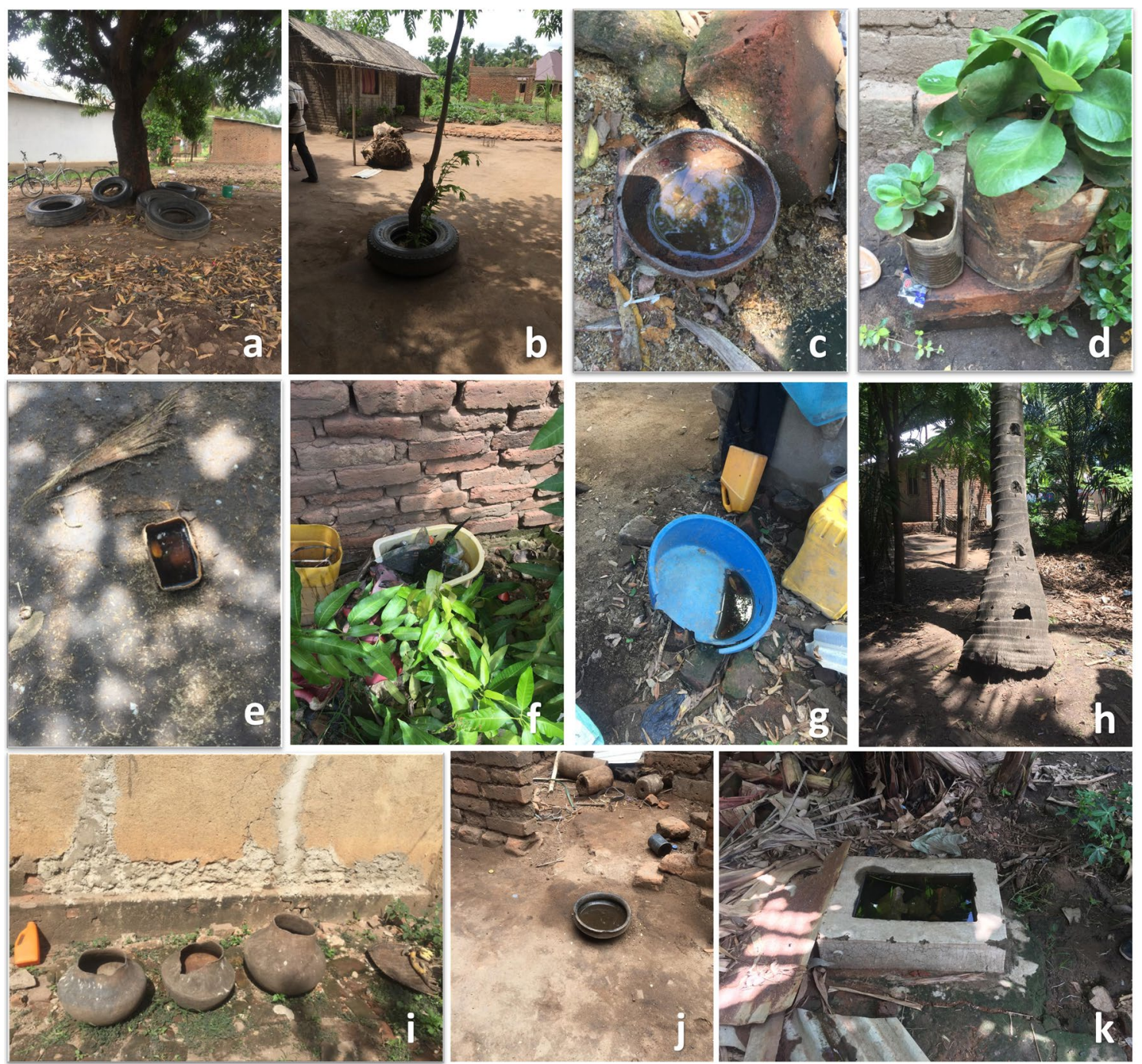

Fig. 3 Various breeding sites identified in the study area: a used vehicle tires, here repurposed by residents as seats; $\mathbf{b}$ used tires kept for protecting trees from pests; $\mathbf{c}$ disposed coconut shells; $\mathbf{d}$ flowerpots; e animal feeding container; $\mathbf{f}$ broken grasses; $\mathbf{g}$ disposed containers; $\mathbf{h}$ coconut tree-holes; $\mathbf{i}$ clay pots; $\mathbf{j}$ small containers; and $\mathbf{j}$ pits such as those at construction sites, in garages, or inspection chambers in waterworks

Ae. aegypti show reduced susceptibility to carbamates and pyrethroids (Fig. 6). Confirmed resistance was detected against only bendiocarb, and only in the rainy season (Fig. 6).

Overall knockdown $\mathrm{KDT}_{50}$ and $\mathrm{KDT}_{95}$ ranged from 7 to $112 \mathrm{~min}$ and 13 to $159 \mathrm{~min}$ respectively (Table 5). The knockdown analysis revealed spatial and seasonal variation. Dieldrin and pirimiphos-methyl consistently achieved slower knockdown across wards, while bendiocarb and deltamethrin exhibited quick knockdown. Knockdown times were not predictive of overall $24 \mathrm{~h}$ mortality. Often mosquitoes were not affected by the insecticides during first $60 \mathrm{~min}$ but mortality was still high after $24 \mathrm{~h}$.

\section{Wing length of adult Ae. aegypti mosquitoes}

Wing length, used here as a proxy for adult size of male and female Ae. aegypti ranged from $1.9 \mathrm{~mm}$ to $3.5 \mathrm{~mm}$ (Fig. 7). The mean $( \pm \mathrm{SD})$ wing length was $2.48 \pm 0.15$ for mosquitoes from Ifakara town, $2.68 \pm 0.23$ in Katindiuka, $2.73 \pm 0.20$ in Lipangalala, $2.33 \pm 0.18$ ) in Mlabani and $2.68 \pm 0.13$ in Viwanja sitini. There was a significant difference in female mosquito wing length across wards (ANOVA: $F_{(4,245)}=45.5, P<0.001$ ). Post-hoc analysis also revealed differences between pairs of wards (Fig. 7). Also, the mean wing length of female Ae. aegypti was generally larger than that of male Ae. aegypti (ANOVA: $F_{(1}$, ${ }_{498)}=365.9, P<0.001$ ). 
Table 3 Larval densities in different aquatic habitats of Ae. aegypti mosquitoes in the dry and rainy seasons in the study area

\begin{tabular}{|c|c|c|c|c|c|}
\hline Habitat type & No. of larvae & No. of habitats & Mean $(95 \% \mathrm{Cl})$ & $\mathrm{RR}(95 \% \mathrm{Cl})$ & $P$-value \\
\hline \multicolumn{6}{|l|}{ Dry season } \\
\hline Used tire & 844 & 51 & 16.5 (15.46-17.70) & 1 & \\
\hline Clay pot & 652 & 44 & $14.8(13.7-16.00)$ & $0.89(0.80-0.99)$ & 0.034 \\
\hline Container & 93 & 24 & $3.9(3.16-4.75)$ & $0.23(0.19-0.29)$ & $<0.01$ \\
\hline Flowerpot & 163 & 9 & $18.1(15.53-21.12)$ & $1.09(0.93-1.29)$ & 0.292 \\
\hline Pit & 96 & 7 & 13.7 (11.23-16.75) & $0.83(0.67-1.02)$ & 0.081 \\
\hline Tree-hole & 199 & 4 & $49.8(43.3-57.17)$ & $3.00(2.58-3.50)$ & $<0.01$ \\
\hline Others & 12 & 6 & $2.0(1.14-3.52)$ & $0.12(0.07-0.21)$ & $<0.01$ \\
\hline \multicolumn{6}{|l|}{ Rainy season } \\
\hline Used tire & 1276 & 55 & $23.2(21.96-24.51)$ & 1 & \\
\hline Clay pot & 978 & 55 & $17.8(16.7-18.93)$ & $0.77(0.70-0.83)$ & $<0.01$ \\
\hline Container & 504 & 27 & $18.7(17.11-20.37)$ & $0.80(0.72-0.89)$ & $<0.01$ \\
\hline Flowerpot & 273 & 17 & $16.1(14.26-18.01)$ & $0.69(0.61-0.79)$ & $<0.01$ \\
\hline Pit & 133 & 7 & 19.0 (16.03-22.52) & $0.82(0.69-0.98)$ & 0.028 \\
\hline Tree-hole & 68 & 4 & $17.0(13.4-21.56)$ & $0.73(0.57-0.94)$ & 0.012 \\
\hline Others & 119 & 5 & $23.8(19.87-28.48)$ & $1.03(0.85-1.24)$ & 0.790 \\
\hline
\end{tabular}

Notes: Category used as reference $\mathrm{R}=1$, means reported here are predicted from generalized linear model which is average of larvae per dipper to number of breeding sites. Used tire was selected as reference because they were present in all study sites. "Others" included positive breeding sites such as disposed shoes, coconut shells, tarpaulins, broken glasses and open plastic bottles

Abbreviations: $\mathrm{RR}$, risk ratio; $\mathrm{Cl}$, confidence interval

Table 4 Results of the logistic regression analysis showing positivity and negativity of habitats of different characteristics for immature Ae. aegypti mosquitoes

\begin{tabular}{|c|c|c|c|c|c|c|c|c|}
\hline \multirow[t]{2}{*}{ Parameter } & \multirow[t]{2}{*}{ Category } & \multirow{2}{*}{$\begin{array}{l}\text { Positive } \\
n(\%)\end{array}$} & \multirow{2}{*}{$\begin{array}{l}\text { Negative } \\
n(\%)\end{array}$} & \multirow[t]{2}{*}{ Total } & \multicolumn{2}{|l|}{ Univariate } & \multicolumn{2}{|l|}{ Multivariate } \\
\hline & & & & & OR $(95 \% \mathrm{Cl})$ & $P$-value & OR (95\% Cl) & $P$-value \\
\hline \multirow[t]{7}{*}{ Habitat type } & Used tires & $89(84)$ & $17(16)$ & 106 & 1 & & 1 & \\
\hline & Clay pot & $81(82)$ & $18(18)$ & 99 & $0.86(0.42-1.78)$ & 0.68 & $0.55(0.21-1.42)$ & 0.216 \\
\hline & Container & $44(86)$ & $7(14)$ & 51 & $1.20(0.46-3.11)$ & 0.70 & $1.07(0.33-3.48)$ & 0.904 \\
\hline & Flowerpot & $22(85)$ & $4(15)$ & 26 & $1.05(0.32-3.44)$ & 0.93 & $0.62(0.13-2.95)$ & 0.551 \\
\hline & Pits & $9(64)$ & $5(36)$ & 14 & $0.34(0.10-1.15)$ & 0.08 & $0.11(0.01-2.54)$ & 0.172 \\
\hline & Tree-hole & $7(88)$ & $1(12)$ & 8 & $1.34(0.15-11.58)$ & 0.79 & $0.92(0.03-31.86)$ & 0.962 \\
\hline & Others & $10(90)$ & $1(9)$ & 11 & $1.91(0.23-15.91)$ & 0.55 & $2.98(0.26-34.82)$ & 0.383 \\
\hline \multirow[t]{3}{*}{ Size } & Large & $36(71)$ & $15(29)$ & 51 & 1 & & 1 & \\
\hline & Medium & $129(84)$ & $25(16)$ & 154 & $2.15(1.03-4.50)$ & 0.042 & $1.73(0.71-4.18)$ & 0.2165 \\
\hline & Small & $97(88)$ & $13(12)$ & 110 & $3.10(1.35-7.17)$ & $<0.001$ & $0.98(0.33-2.89)$ & 0.966 \\
\hline \multirow[t]{2}{*}{ Season } & Dry season & $97(67)$ & $48(33)$ & 145 & 1 & & 1 & \\
\hline & Rainy season & $165(97)$ & $5(3)$ & 170 & $16.30(6.30-42.40)$ & $<0.001$ & $19.73(6.61-58.94)$ & $<0.001$ \\
\hline \multirow[t]{2}{*}{ Movability } & Immovable & $20(74)$ & $7(26)$ & 27 & 1 & & 1 & \\
\hline & Movable & $242(84)$ & $46(16)$ & 288 & $1.80(0.74-4.60)$ & 0.192 & $0.36(0.03-5.24)$ & 0.46 \\
\hline \multirow[t]{3}{*}{ Turbidity } & Clear & $145(88)$ & $20(12)$ & 165 & 1 & & 1 & \\
\hline & Turbid & $109(83)$ & $22(17)$ & 131 & $0.68(0.36-1.32)$ & 0.254 & $0.79(0.38-1.67)$ & 0.5417 \\
\hline & Very turbid & $8(42)$ & $11(58)$ & 19 & $0.10(0.03-0.27)$ & $<0.001$ & $0.13(0.04-0.44)$ & $<0.001$ \\
\hline \multirow[t]{3}{*}{ Shades } & Full & $115(86)$ & $19(14)$ & 134 & 1 & & 1 & \\
\hline & Partial & $126(81)$ & $29(19)$ & 155 & $0.72(0.38-1.35)$ & 0.303 & $0.74(0.35-1.60)$ & 0.45 \\
\hline & None & $21(81)$ & $5(19)$ & 26 & $0.70(0.23-2.06)$ & 0.511 & $0.43(0.09-1.92)$ & 0.27 \\
\hline \multirow[t]{2}{*}{ Water source } & Domestic & $12(63)$ & $7(36)$ & 19 & 1 & & & \\
\hline & Rainwater & $250(84)$ & $46(16)$ & 296 & $3.17(1.19-8.45)$ & 0.02 & $1.11(0.28-4.39)$ & 0.87 \\
\hline
\end{tabular}



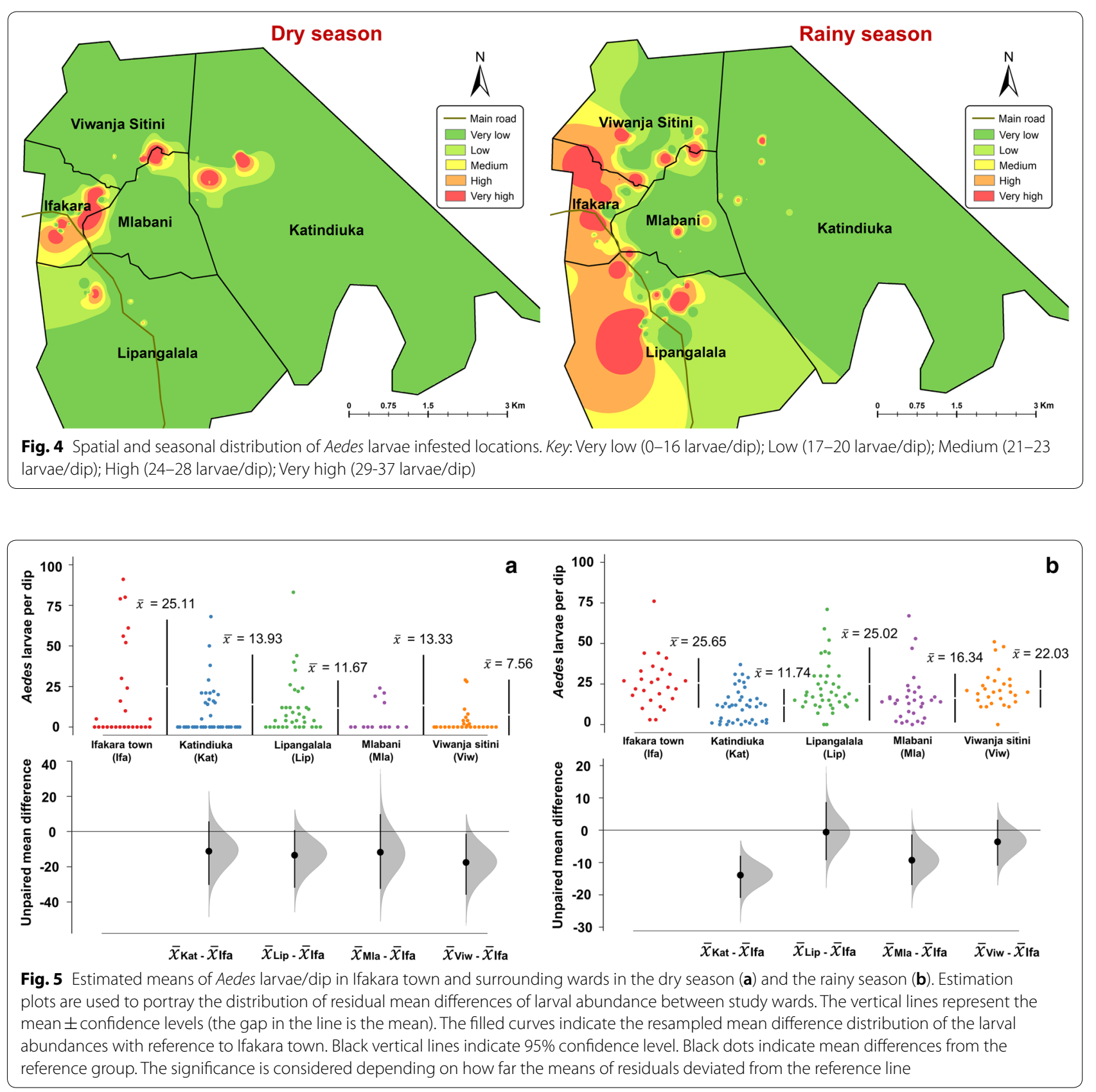

\section{Discussion}

In Tanzania, the majority of studies conducted on arbovirus vectors are in response to outbreaks, and are often concentrated in large urban areas [11]. Basic ecological studies to understand the distribution and behavior of the vectors or their responses to interventions remain very few. This study involved an exploratory survey of $A e$. aegypti mosquitoes in the small town of Ifakara and its surrounding wards in south-eastern Tanzania. The findings therefore constitute essential baseline data on $A e$. aegypti mosquitoes in this area where no outbreak has previously been reported, yet the risk is high. Given previous reports of arboviral infections such as dengue and chikungunya in neighboring districts [7], it is crucial to invest on basic studies to improve our understanding of the ecology of the vectors, so as to boost control options.

The main finding was that larval indices, CI, HI and $\mathrm{BI}$, are high enough to signal significant risk of Aedes-borne diseases in the area. In the rainy season in particular, house and container indices in all wards 


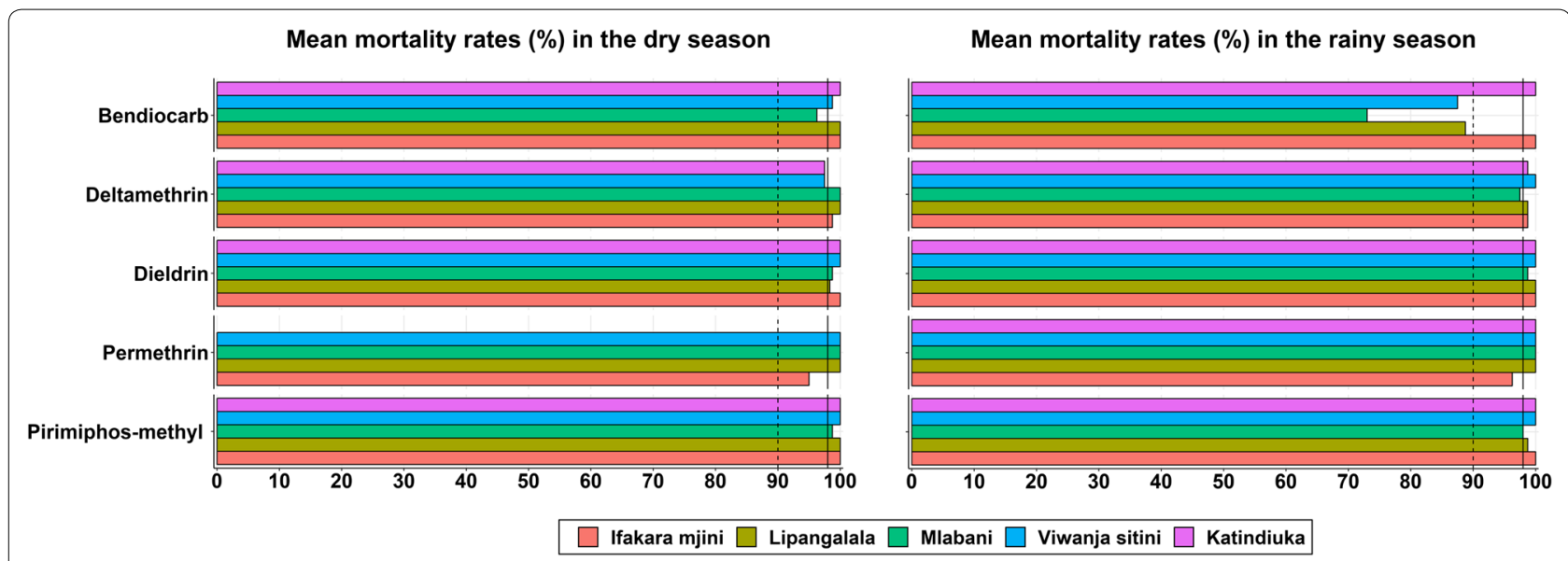

Fig. 6 Mean mortality demonstrating susceptibility status of Ae. aegypti in the dry and rainy seasons. The solid lines ( $\geq 98 \%$ mortality) indicate that mosquitoes are fully susceptible to insecticide, while the dotted lines (90-98\% mortality) indicate possible resistance requiring confirmation

Table 5 Knock-down times of Ae. aegypti mosquitoes collected from different sites

\begin{tabular}{|c|c|c|c|c|c|}
\hline \multirow[t]{2}{*}{ Insecticide } & \multirow[t]{2}{*}{ Ward } & \multicolumn{2}{|l|}{ Dry season } & \multicolumn{2}{|l|}{ Rain season } \\
\hline & & $\mathrm{KDT}_{50} \pm \mathrm{SE}(\mathrm{min})$ & $\mathrm{KDT}_{95} \pm \mathrm{SE}(\mathrm{min})$ & $\mathrm{KDT}_{50} \pm \mathrm{SE}(\mathrm{min})$ & $\mathrm{KDT}_{95} \pm \mathrm{SE}$ (min) \\
\hline \multirow[t]{5}{*}{ Bendiocarb } & Ifakara town & $21.44 \pm 4.52$ & $28.68 \pm 8.95$ & $14.58 \pm 6.28$ & $30.26 \pm 12.90$ \\
\hline & Katindiuka & $16.89 \pm 3.05$ & $22.15 \pm 6.17$ & $22.85 \pm 6.68$ & $39.34 \pm 13.45$ \\
\hline & Lipangalala & $30.00 \pm 5.82$ & $41.16 \pm 10.29$ & $32.94 \pm 8.04$ & $53.86 \pm 15.43$ \\
\hline & Mlabani & $25.13 \pm 6.94$ & $42.28 \pm 13.66$ & $30.77 \pm 6.48$ & $44.18 \pm 11.70$ \\
\hline & Viwanja sitini & $28.91 \pm 5.67$ & $38.99 \pm 10.08$ & $39.77 \pm 9.18$ & $63.91 \pm 18.76$ \\
\hline \multirow[t]{5}{*}{ Deltamethrin } & Ifakara town & $9.67 \pm 3.56$ & $14.11 \pm 5.78$ & $6.19 \pm 5.9$ & $17.16 \pm 8.83$ \\
\hline & Katindiuka & $11.45 \pm 4.42$ & $19.95 \pm 7.65$ & $12.00 \pm 9.60$ & $37.44 \pm 18.07$ \\
\hline & Lipangalala & $29.09 \pm 46.16$ & $31.59 \pm 76.50$ & $12.46 \pm 3.44$ & $18.52 \pm 6.27$ \\
\hline & Mlabani & $7.20 \pm 4.58$ & $12.30 \pm 5.27$ & $16.41 \pm 13.99$ & $59.19 \pm 30.42$ \\
\hline & Viwanja sitini & $7.12 \pm 4.48$ & $13.08 \pm 5.75$ & $17.64 \pm 5.45$ & $30.20 \pm 11.55$ \\
\hline \multirow[t]{5}{*}{ Dieldrin } & Ifakara town & $36.02 \pm 7.32$ & $52.69 \pm 13.26$ & $75.43 \pm 49.31$ & $101.68 \pm 103.19$ \\
\hline & Katindiuka & $40.73 \pm 7.56$ & $57.80 \pm 13.96$ & $22.90 \pm 8.44$ & $47.57 \pm 17.40$ \\
\hline & Lipangalala & $43.32 \pm 5.95$ & $53.86 \pm 10.68$ & $85.57 \pm 70.37$ & $146.57 \pm 154.15$ \\
\hline & Mlabani & $70.90 \pm 33.93$ & $102.46 \pm 75.05$ & $40.21 \pm 8.70$ & $62.23 \pm 17.21$ \\
\hline & Viwanja sitini & $49.01 \pm 6.89$ & $62.59 \pm 13.51$ & $66.17 \pm 370.89$ & $70.70 \pm 620.79$ \\
\hline \multirow[t]{5}{*}{ Permethrin } & Ifakara town & $12.69 \pm 7.55$ & $32.13 \pm 14.93$ & $7.20 \pm 7.59$ & $23.42 \pm 12.58$ \\
\hline & Katindiuka & - & - & $10.56 \pm 8.14$ & $30.66 \pm 15.25$ \\
\hline & Lipangalala & $8.52 \pm 4.38$ & $14.87 \pm 5.95$ & $12.28 \pm 2.60$ & $16.27 \pm 4.68$ \\
\hline & Mlabani & $29.83 \pm 7.21$ & $47.19 \pm 13.58$ & $9.54 \pm 8.73$ & $30.60 \pm 15.78$ \\
\hline & Viwanja sitini & $15.38 \pm 4.41$ & $24.73 \pm 9.57$ & $18.28 \pm 3.17$ & $23.45 \pm 7.01$ \\
\hline \multirow[t]{5}{*}{ Pirimiphos-methyl } & Ifakara town & $75.66 \pm 44.78$ & $109.97 \pm 95.41$ & $71.03 \pm 37.01$ & $114.39 \pm 83.36$ \\
\hline & Katindiuka & $78.03 \pm 50.32$ & $125.04 \pm 109$ & $26.66 \pm 7.90$ & $48.30 \pm 15.75$ \\
\hline & Lipangalala & $79.14 \pm 52.26$ & $123.36 \pm 111.14$ & $32.36 \pm 10.12$ & $63.19 \pm 22.59$ \\
\hline & Mlabani & $60.00 \pm 15.83$ & $84.06 \pm 38.22$ & $43.72 \pm 8.41$ & $63.61 \pm 16.69$ \\
\hline & Viwanja sitini & $83.29 \pm 102.4$ & $108.97 \pm 193.88$ & $39.75 \pm 14.95$ & $84.60 \pm 41.95$ \\
\hline
\end{tabular}

Note: In each experiment there were six replicates and 120-150 Ae. aegypti female mosquitoes

Abbreviations: $\mathrm{SE}$, standard error; $\mathrm{KDT}_{50}$, time taken for $50 \%$ of the tested mosquitoes to be knocked-down; $\mathrm{KDT}_{95}$ time taken for $95 \%$ of the tested mosquitoes to be knocked-dow 

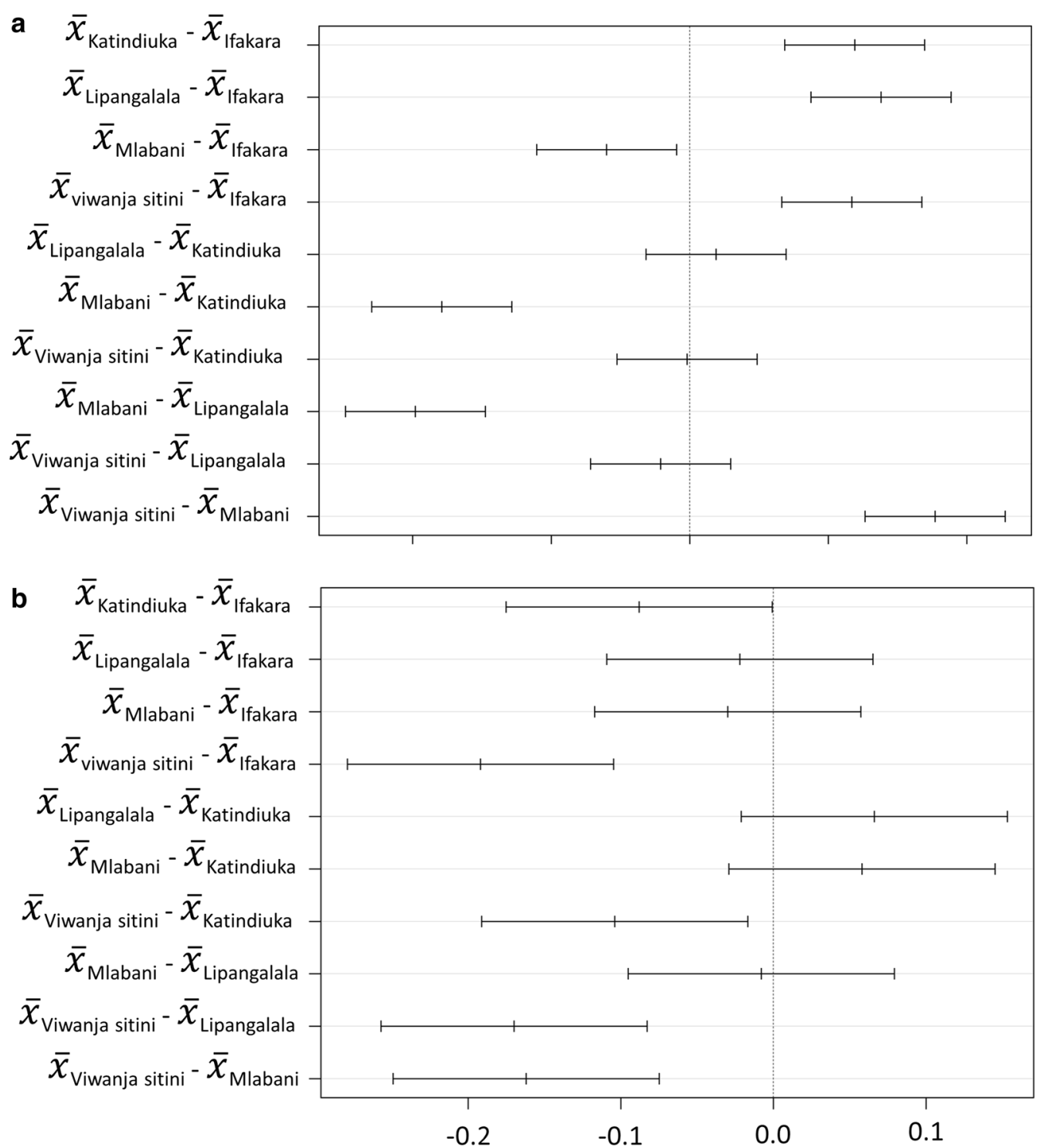

Fig. 7 Differences in mean wing length between wards. Pairwise comparisons are shown at 95\% confidence levels for female (a) and male (b) Aedes aegypti mosquitoes

exceeded the value of 5.0, specified by WHO for actionable arboviral infections risk [38, 39]. Dry season risk was however confined to fewer wards though not completely absent from the rest of the wards. Immature $A e$. aegypti infestation varied between wards and seasons, but remained significant even in the dry season. This was expected since Aedes mosquitoes typically breed in man-made containers not fully dependent on rainfall. Besides, the vectors have fewer options of breeding sites in the dry season hence elevating container level of infestation with immature Ae. aegypti (Table 1). On the contrary, aquatic habitats were relatively large in number during the rainy season, resulting in lower positivity rates (Table 1). This higher level of container infestation in the dry season concur with the study conducted in northern regions of Ghana which showed that, indices in the dry season were aggravated by poor water supply system in the area. As a result, water stored for domestic purposes stayed long enough to enable Aedes mosquito breeding [40].

Similar to earlier research, this study has shown that Ae. aegypti prefers breeding in clean and stagnant waters [19, 20, 41]. Common habitats for Ae. aegypti were used tires, clay pots, flowerpots, containers, coconut treeholes, pits, and on rare occasions disposed shoes, cooking pans, broken grasses and tarpaulins. The majority of 
these habitats were easy to discard, indicating an opportunity for proper waste management and environmental management as effective options for Aedes control, especially if used alongside traditional larviciding. As already highlighted by several previous studies, tires in particular serve as important breeding sites for Ae. aegypti because they can hold water for long periods even in the dry season $[11,19,42]$. The multiple applications of used tires in the area will, however, complicate efforts to effectively dispose of the tires. For example, people use these tires as make-shift chairs, for playing by kids, for planting trees (residents believed that tires prevent plant pests), and for vehicle repairs.

A major natural breeding site in the area was coconut trees, which had artificial holes created for climbing during the coconut harvesting period. These holes served as the perfect breeding sites for Ae. aegypti mosquitoes. This study therefore recommends that coconut tree-holes be filled with sand to prevent rainwater from stagnating. Clay pots were also common in Katindiuka and Lipangalala wards, where they were mostly used for collecting rainwater for domestic use. Unfortunately, residents were not adequately aware that these pots are breeding sites for Ae. aegypti mosquitoes. Rare habitats such as disposed coconut shells, broken glass, animal feeding containers, tarpaulins and discarded plastic shoes were also observed, which produced high larval abundance (larvae/dipper). Larval abundance was influenced by the size of habitats and the volume of water present in breeding sites.

During the data collection period, surrounding communities were explained about mosquito breeding behaviors and diseases they transmit to raise awareness. This led to a better understanding and greater engagement of the communities in this work. Some breeding sites observed during the first visit were not there during subsequent visit as people became aware of the risks and hence proactively removed or covered potential habitats. This observation highlights the potential of educating communities about breeding sources of Ae. aegypti and participatory control efforts. In Tanzania, the government is already implementing monthly clean-up campaigns, which could be leveraged to achieve such gains. Moreover, efforts to reduce mosquito population can prioritize areas identified with higher risk.

Mosquito sizes play an important role in overall ability of the individual mosquitoes to pick up and disseminate pathogens, including viruses $[43,44]$. For example, smaller mosquitoes tend to have more contacts with hosts as they need more frequent blood meals than larger mosquitoes, a phenomenon which could increase transmission [44]. In the present study, the wing length measurements for Ae. aegypti ranged between $1.9-3.5 \mathrm{~mm}$.
The differences between administrative wards may imply that some of the wards could harbor vectors with greater vectorial capacity than others, but the actual extent to which such variations affect pathogen spread in this area remains to be investigated. On the other hand, larger mosquitoes have been demonstrated to be more resistant toward insecticides [45], which may also influence susceptibility of those mosquitoes to public health insecticides. This study therefore provides a baseline assessment of wing lengths, so that any future changes can be compared against current status of the insecticide-susceptible Ae. aegypti populations. It is recognized that statistical variability in wing length measurements may be greater among mosquitoes collected at their aquatic stages compared to those collected as adults [46]. However, in this study all wing measurements were taken on mosquitoes collected at aquatic stages, thus minimizing any potential differences associated with the mosquito life-cycle stage.

Finally, Ae. aegypti mosquitoes in the area were assessed for how they would respond to control by commonly available insecticides. Fortunately, this study showed that the mosquito populations in the Ifakara area are still generally susceptible to most insecticide classes. Given that Ae. aegypti mosquitoes are mostly outdoor bitters [47], their exposure to chemical indoor interventions such as insecticide-treated nets is likely low. Interestingly, it was observed that in a few wards, the mosquitoes were resistant to bendiocarb during the rainy season but not in the dry season. Future research should examine potential environmental drivers and the extent of these phenotypes. Previous research has already demonstrated fine-scale spatial and temporal differences in insecticide susceptibility of both Anopheles [48] and Culex mosquitoes [49] to pesticides.

Since this study was the first of its kind in this geographical area, there were no immediate comparisons for the resistance profiles. However, in studies carried out in Dar es Salaam, Peru and Burkina Faso, resistance to pyrethroids and organophosphate was obvious [20, 50, 51]. Reduced susceptibility to pyrethroids observed in some of assays, and the resistance seen against bendiocarb in the rainy season are however signs that we must remain vigilant as insecticide resistance could rapidly spread among the vector populations once active control programmes begin. This would therefore mean that environmental management, including larval habitats search and removal, should be an important component of any antiAedes campaigns. As most habitats are those that can be discarded, combinations of insecticidal and non-insecticidal approaches would likely be effective.

Although the main objectives were successfully completed, this study also had various limitations. First, larvae and pupae were only collected in the selected grids, 
yet the wards were not of the same surface area (Fig. 2). It is possible therefore that some of the Aedes indices might have been underestimated. This study therefore recommends that future studies should consider all the grids occupied by human habitations and building.

Secondly, the WHO standard dose specified for Anopheles mosquitoes was adopted in this study, as there is still no comprehensive WHO guideline for assessing susceptibility of Aedes mosquitoes. However, some of these insecticides, such as pirimiphos-methyl, permethrin and deltamethrin already have diagnostic concentrations specific for Aedes mosquitoes. Therefore, if the right concentration had been used, the results might have been different. For instance, results for permethrin $(0.75 \%)$ demonstrated susceptibility toward standard concentration for Anopheles, which is three times the Aedes standard concentration $(0.25 \%)$ indicating that the result of permethrin obtained here might have been overrated. This study therefore recommends that future studies should incorporate appropriate guidelines for the species.

\section{Conclusions}

To our knowledge, this is the first study on ecology and insecticide susceptibility of Ae. aegypti in the Ifakara area, and will provide a basis for future evaluation of its role in pathogen transmission, as well as options for its control. Infestation levels observed indicate that immediate vector control campaigns, coupled with targeted surveys of Aedes-borne diseases in humans, should be conducted to track and prevent potential outbreaks. The larval indices (container index, house index and Breteaux index) are high enough to signal significant risk of Aedes-borne diseases in the area. Fortunately, Ae. aegypti in the area are still susceptible to majority of insecticides used in public health, indicating there are still opportunities to include insecticides in the Aedes control programmes. Since most habitats were those that can be discarded, integrating concepts of environmental management, insecticide use, and community engagement could yield significant progress. While used tires, discarded containers and flowerpots are key habitats for Aedes in the area, this study also identified coconut harvesting as an important risk factor, and the associated tree-holes as vital targets for Aedes control.

\footnotetext{
Abbreviations

ANOVA: analysis of variance; BI: Breteaux Index; Cl: Container Index; CIESIN: Centre for International Earth Science Information Network; ESRI, USA: Environmental Systems Research Institute, USA; GPS: geographical position system; GVCR: Global Vector Control Response; HI: House Index; HRSL: high resolution settlement layer; IDW: inverse distance weighted; IHI: Ifakara Health Institute; KDT: knock-down time; MRCC: Medical Research Coordinating Committee; NIMR: National Institutes of Medical Research; OR: odds ratio; RR: relative risk; WHO: World Health Organization.
}

\section{Acknowledgements}

We thank Ifakara community leaders and local residents in general for allowing us to work in their areas. We thank all volunteers who participated in the data collection (Moses Mlaganile, Samwel Makayula, Hamisi Kipongo, Gerald Tamayamali and Rabson Namtwanga). We thank Japhet Kihonda for offering training to our volunteers and providing technical support. We also express our sincere thanks to Outdoor Mosquito Control (OMC) research team members, including Marceline Finda, Doreen Siria, Rukiyah Mohammed, Anold Mbando, Kyeba Swai, Emmanuel Hape and Pinda Polius, for providing technical and logistical assistance throughout the study period.

\section{Authors' contributions}

NFK was involved in conceptualization and designing of the study, data collection, data entry and formal analysis, conducting bioassay tests, producing maps and writing the manuscript. FOO was involved in conceptualization, study design, supervision and manuscript revision. HSN was involved in analysis, reviewing and supervision. AJL, SAM and EWK were involved in study design and producing maps, BJM and DSM were involved in data collection and reviewing. All authors read and approved the final manuscript.

\section{Funding}

Masters scholarship in Public Health Research awarded to the lead author funded by African Development Bank (AfDB). Material, equipment and some of the field activities were supported through USAID funded Grant (Grant Number: AID-OAA-F-16-00093) awarded to FOO. FOO was also supported by a Wellcome Trust Intermediate Fellowship, Grant Number 102350.

\section{Availability of data and materials}

Data supporting the conclusions of this article are included within the article. All raw data for this study will be available upon request the lead author (NFK).

\section{Ethics approval and consent to participate}

Approval for this study was obtained from institutional review board of Ifakara Health Institute (Ref: IHI/IRB/No: 10-2017), and from the Medical Research Coordinating Committee (MRCC) at the National Institutes of Medical Research (NIMR), (Ref: NIMR/HQ/R.8a/Nol. IX/2555). Meetings with local leaders were held to highlight objectives, benefits and risks associated with the study. Informed consent was obtained from all owners of property around which the mosquito surveys were conducted. Approval for publishing this paper was obtained from National Institutes of Medical Research (NIMR), (Ref: NIMR/ HQ/P.12 Vol. XXIX/9)

\section{Consent for publication}

Not applicable.

\section{Competing interests}

The authors declare that they have no competing interests.

\section{Author details}

${ }^{1}$ Environmental Health and Ecological Sciences Department, Ifakara Health Institute, P. O. Box 53, Ifakara, Tanzania. ${ }^{2}$ Faculty of Health Science, School of Public Health, University of the Witwatersrand, Johannesburg, South Africa. ${ }^{3}$ School of Life Science and Biotechnology, Nelson Mandela African Institution of Science and Technology, P. O. Box 447, Arusha, Tanzania. ${ }^{4}$ Institute of Biodiversity, Animal Health and Comparative Medicine, University of Glasgow, Glasgow G128QQ, UK.

Received: 28 November 2019 Accepted: 29 January 2020

Published online: 07 February 2020

\footnotetext{
References

1. Bhatt S, Weiss DJ, Cameron E, Bisanzio D, Mappin B, Dalrymple U, et al. The effect of malaria control on Plasmodium falciparum in Africa between 2000 and 2015. Nature. 2015;526:207-11.

2. WHO. World malaria report 2018. Geneva: World Health Organization; 2018. http://apps.who.int/iris.

3. Golding N, Wilson AL, Moyes CL, Cano J, Pigott DM, Velayudhan R, et al. Integrating vector control across diseases. BMC Med. 2015;13:249.
} 
4. WHO. Global vector control response 2017-2030: a strategic approach to tackle vector-borne diseases. Geneva: World Health Organization; 2017.

5. WHO. Guidelines for dengue surveilllance and mosquito control. Geneva: World Health Organization; 2003.

6. Biswal S, Reynales H, Saez-Llorens X, Lopez P, Borja-Tabora C, Kosalaraksa $P$, et al. Efficacy of a tetravalent dengue vaccine in healthy children and adolescents. New Engl J Med. 2019;381:2009-19.

7. Chipwaza B, Mugasa JP, Selemani M, Amuri M, Mosha F, Ngatunga SD, et al. Dengue and chikungunya fever among viral diseases in outpatient febrile children in Kilosa District Hospital, Tanzania. PLoS Negl Trop Dis. 2014;8:e33.

8. Patrick BN, Kinimi E, Shayo MJ, Ang SO, Weyer J, van Vuren PJ, et al. Distribution and diversity of mosquitoes and the role of Aedes in the transmission of arboviruses in selected districts of Tanzania. Int J Mosa Res. 2018;5:53-60.

9. Hertz JT, Munishi OM, Ooi EE, Howe S, Lim WY, Chow A, et al. Chikungunya and dengue fever among hospitalized febrile patients in northern Tanzania. Am J Trop Med Hyg. 2012;86:171-7.

10. Kajeguka DC, Kaaya RD, Mwakalinga S, Ndossi R, Ndaro A, Chilongola JO, et al. Prevalence of dengue and chikungunya virus infections in northeastern Tanzania: a cross sectional study among participants presenting with malaria-like symptoms. BMC Infect Dis. 2016;16:183.

11. Mboera LEG, Mweya CN, Rumisha SF, Tungu PK, Stanley G, Makange $M R$, et al. The risk of dengue virus transmission in Dar es Salaam, Tanzania, during an epidemic period of 2014. PLoS Negl Trop Dis 2016;10:e0004313.

12. Vairo F, Nicastri E, Meschi S, Schepisi MS, Paglia MG, Bevilacqua N, et al Seroprevalence of dengue infection: a cross-sectional survey in mainland Tanzania and on Pemba Island, Zanzibar. Int J Infect Dis. 2012;16:2011-3.

13. Vairo F, Nicastri E, Yussuf SM, Cannas A, Meschi S, Mahmoud MA, et al. IgG against dengue virus in healthy blood donors, Zanzibar, Tanzania. Emerg Infect Dis. 2014;20:465-8.

14. WHO. Weekly bulletin on outbreaks and other emergencies. Bull World Health Organ. Geneva: World Health Organization; 2018. p. 1-20.

15. Stoler J, al Dashti R, Anto F, Fobil JN, Awandare GA. Deconstructing "malaria": West Africa as the next front for dengue fever surveillance and control. Acta Trop. 2014;134:58-65.

16. Wiwanitkit $\mathrm{V}$. Dengue fever: diagnosis and treatment. Expert Rev Anti Infect Ther. 2010;8:841-5.

17. Simmons CP, McPherson K, Van Chau NV, Tam DH, Young P, Mackenzie $J$, et al. Recent advances in dengue pathogenesis and clinical management. Vaccine. 2015;33:7061-8.

18. Bataille A, Cunningham AA, Cruz M, Cedeno V, Goodman SJ. Seasonal effects and fine-scale population dynamics of Aedes taeniorhynchus, a major disease vector in the Galapagos Islands. Mol Ecol. 2010;19:4491-504.

19. Getachew D, Tekie H, Gebre-Michael T, Balkew M, Mesfin A. Breeding sites of Aedes aegypti: potential dengue vectors in Dire Dawa, East Ethiopia. Interdiscip Perspect Infect Dis. 2015;2015:706276.

20. Mathias L, Baraka V, Philbert A, Innocent E, Francis F, Nkwengulila G, et al. Habitat productivity and pyrethroid susceptibility status of Aedes aegypti mosquitoes in Dar es Salaam, Tanzania. Infect Dis Poverty. 2017;6:102.

21. WHO. Treatment, prevention and control global strategy for dengue prevention and control 2012-2020. Geneva: World Health Organization; 2012. https://www.who.int/denguecontrol/9789241504034/en/.

22. WHO. Vector surveillance and control. Geneva: World Health Organization; 1997. p. 48-59. https://www.who.int/csr/resources/publications/ dengue/048-59.pdf?ua=1. http://www.who.int/csr/resources/publicatio ns/dengue/Denguepublication/en/.

23. WorldData.info. Climate in Morogoro, Tanzania. https://www.worlddata. info/africa/tanzania/climate-morogoro.php. Accessed 10 Oct 2019.

24. United Republic of Tanzania. 2012 population and housing census: population distribution by administrative areas. Dar es Salaam: National Bureau of Statistics and Office of Chief Government Statistician; 2013.

25. Mwangungulu SP, Sumaye RD, Limwagu AJ, Siria DJ, Kaindoa EW, Okumu FO. Crowdsourcing vector surveillance: using community knowledge and experiences to predict densities and distribution of outdoor-biting mosquitoes in rural Tanzania. PLoS One. 2016;11:e0156388.

26. Geubbels E, Amri S, Levira F, Schellenberg J, Masanja H, Nathan R. Health and demographic surveillance system profile: the Ifakara rural and urban health and demographic surveillance system (Ifakara HDSS). Int J Epidemiol. 2015;44:848-61.

27. Facebook Connectivity Lab and Center for International Earth Science Information Network_CIESIN_Columbia University. 2016. High Resolution Settlement Layer (HRSL). Source Imag. HRSL @ 2016 Digit.

28. Center for Disease Control. CDC Key_Mosquitoes: Pictorial Key to US Genera. https://www.cdc.gov/nceh/ehs/Docs/Pictorial_Keys/Mosquitoes .pdf.

29. WHO. Test procedures for insecticide resistance monitoring in malaria vector mosquitoes. 2nd ed., World Health Organ Tech Rep SerGeneva: World Health Organisation; 2016. p. 1-22.

30. WHO. Monitoring and managing insecticide resistance in Aedes mosquito populations: interim guidance for entomologists. Geneva: World Health Organization; 2016.

31. R Development Core Team. R: a language and environment for statistical computing. Vienna, Austria: R Foundation for Statistical Computing; 2016. https://www.R-project.org/.

32. WHO. Vector surveillance. Geneva: World Health Organization; 2017. https ://www.who.int/denguecontrol/monitoring/vector_surveillance/en/. Accessed 14 Oct 2019.

33. Santoso PB, Apriyono A, Suryani R. Inverse distance weighting interpolated soil properties and their related landslide occurrences. In: MATEC Web Conference. EDP Sciences; 2018. Vol. 195. p. 3013.

34. Bailey TC, Gatrell AC. Interactive spatial data analysis. Longman Scientific \& Technical; 1995. http://www.personal.psu.edu/faculty/f/k/fkw/rsoc597/ Introduction.pdf.

35. Verdonschot PFM, Besse-Lototskaya AA. Flight distance of mosquitoes (Culicidae): a metadata analysis to support the management of barrier zones around rewetted and newly constructed wetlands. Limnologica. 2014:45:69-79

36. WHO. Dengue control. Geneva: World Health Organization; 2018. https:// www.who.int/denguecontrol/mosquito/en/.

37. WHO. Guidelines for Denque surveillance and mosquito control, 2nd edition. Geneva: World Health Organization; 2003. https://apps.who.int/iris/ handle/10665/206987.

38. WHO. Vector surveillance and control at ports, airports, and ground crossings. Geneva: World Health Organization; 2016. https://apps.who.int/iris/ bitstream/handle/10665/204660/9789241549592 eng.pdf?sequence=1.

39. WHO. Technical guide for a system of yellow fever surveillance. Wkly Epidemiol Rec. 1971;46:493-500.

40. Appawu M, Dadzie S, Abdul H, Asmah H, Boakye D, Wilson M, et al. Surveillance of viral haemorrhagic fevers in Ghana: entomological assessment of the risk of transmission in the northern regions. Ghana Med J. 2010;40:3.

41. Simard F, Nchoutpouen E, Toto JC, Fontenille D. Geographic distribution and breeding site preference of Aedes albopictus and Aedes aegypti (Diptera: Culicidae) in Cameroon, Central Africa. J Med Entomol. 2005:42:726-31.

42. Ngugi HN, Mutuku FM, Ndenga BA, Musunzaji PS, Mbakaya JO, Aswani $\mathrm{P}$, et al. Characterization and productivity profiles of Aedes aegypti (L.) breeding habitats across rural and urban landscapes in western and coastal Kenya. Parasit Vectors. 2017;10:331.

43. Paulson SL, Hawley WA. Effect of body size on the vector competence of field and laboratory populations of Aedes triseriatus for La Crosse virus. J Am Mosq Control Assoc. 1991;7:170-5.

44. Alto BW, Reiskind MH, Lounibos LP. Size alters susceptibility of vectors to dengue virus infection and dissemination. Am J Trop Med Hyg. 2008;79:688-95.

45. Oliver SV, Brooke BD. The effect of larval nutritional deprivation on the life history and DDT resistance phenotype in laboratory strains of the malaria vector Anopheles arabiensis. Malar J. 2013;12:44.

46. Schneider JR, Morrison AC, Astete H, Scott TW, Wilson ML. Adult size and distribution of Aedes aegypti (Diptera: Culicidae) associated with larva habitats in Iquitos, Peru. J Med Entomol. 2004:41:634-42.

47. Kamgang B, Nchoutpouen E, Simard F, Paupy C. Notes on the bloodfeeding behavior of Aedes albopictus (Diptera: Culicidae) in Cameroon Parasit Vectors. 2012;5:57.

48. Matowo NS, Munhenga G, Tanner M, Coetzee M, Feringa WF, Ngowo $\mathrm{HS}$, et al. Fine-scale spatial and temporal heterogeneities in insecticide resistance profiles of the malaria vector, Anopheles arabiensis in rural south-eastern Tanzania. Wellcome Open Res. 2017:2:96. 
49. Matowo NS, Abbasi S, Munhenga G, Tanner M, Mapua SA, Oullo D, et al. Fine-scale spatial and temporal variations in insecticide resistance in Culex pipiens complex mosquitoes in rural south-eastern Tanzania. Parasit Vectors. 2019;12:413.

50. Pinto J, Palomino M, Mendoza-Uribe L, Sinti C, Liebman KA, Lenhart A. Susceptibility to insecticides and resistance mechanisms in three populations of Aedes aegypti from Peru. Parasit Vectors. 2019;12:494.

51. Sombié A, Saiki E, Yaméogo F, Sakurai T, Shirozu T, Fukumoto S, et al. High frequencies of F1534C and V1016l kdr mutations and association with pyrethroid resistance in Aedes aegypti from Somgandé (Ouagadougou), Burkina Faso. Trop Med Health. 2019;47:2.

\section{Publisher's Note}

Springer Nature remains neutral with regard to jurisdictional claims in published maps and institutional affiliations.
Ready to submit your research? Choose BMC and benefit from:

- fast, convenient online submission

- thorough peer review by experienced researchers in your field

- rapid publication on acceptance

- support for research data, including large and complex data types

- gold Open Access which fosters wider collaboration and increased citations

- maximum visibility for your research: over $100 \mathrm{M}$ website views per year

At BMC, research is always in progress.

Learn more biomedcentral.com/submissions 